\title{
Science Education: Our Professional Responsibility
}

\author{
Thomas G Stoebe* \\ Materials Science and Engineering, USA
}

ISSN: 2578-0255

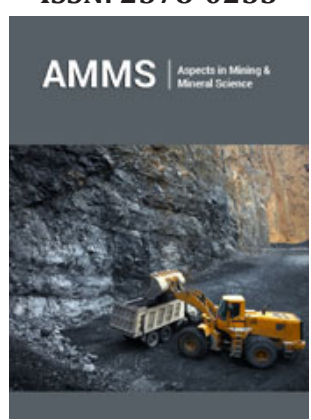

*Corresponding author: Thomas G Stoebe, Professor Emeritus, Materials Science and Engineering, USA

Submission: 酒 November 11, 2019

Published: : November 13, 2019

Volume 4 - Issue 1

How to cite this article: Thomas G Stoebe. Science Education: Our Professional Responsibility. Aspects Min Miner Sci.4(1). AMMS.000579.2019.

DOI: 10.31031/AMMS.2019.04.000579

Copyright@ Thomas G Stoebe, This article is distributed under the terms of the Creative Commons Attribution 4.0 International License, which permits unrestricted use and redistribution provided that the original author and source are credited.

\section{Opinion}

Youngsters play with rocks of all sorts, whatever they find. And they dig in the dirt and sand to see what's there. When they find an interesting rock or dig up a treasure, they use their experience to try to decide what it is and perhaps where the item come from. If a rock is especially colorful, or if they dig up what may be a "treasure," their interest increases and they notice the differences in shape, composition and properties (hardness, color, etc.). What they are doing is scientific exploration and what they are experiencing is applied science-BUT THEY DON'T KNOW IT! The question is, why don't we, as professionals whose careers are based on applied science, help educate the youngsters on how the differences they observe in objects is the result of differences in materials and their properties and that these are the essence of scientific studies?

Minerals and the products that are extracted from them, be they metals, ceramics, glass or plastic, are the basic "stuff" of modern technology. We need better means of showing students WHY minerals come in different colors. And HOW the properties of a material can depend on its composition. And ultimately WHEN materials can be combined to produce products to solve specific problems. Exploring our natural world, as noted above, is FUN! Likewise, Science is FUN and linking exploration with science makes science fun once students realize that applications of science are everywhere! At that point, the applications of science in our technology becomes more apparent, providing students with possible career goals or at least providing them with an understanding of the need for a science base for our modern world. Educational curricula for young and old in this area are utilized by knowledgeable educators for all ages of student, from elementary school to college and to technology education. Sometimes, just a pointer from a professional will help the educator to bring out the applications of the science they teach. Examples of ways of enhancing students' interest and understanding of science and its many applications include:

a. Characterizing items that students might collect in their back yard or at the beach in terms of color, transparency, texture, hardness, strength, ductility, etc. This can be an exercise in categorization, followed by testing of properties, and undertaken in a variety of contexts. Depending on student level, different categories of solids can be found and in some cases more advanced test techniques can be explored. Here, the focus needs to be on a basic explanation of the phenomena observed.

b. Developing the idea that the same material can have different properties if they are produced differently. This applies equally well to rocks as it does to metals. Here we can demonstrate the resulting effect of differential rates of cooling during solidification of geological formations as well as of steel, and can be carried further to identify the relationship between the heat treatment and changes in materials properties.

c. Showing how a brittle material can be made stronger depending on composition, structure and how stresses are applied. This can be demonstrated using glass (window vs. tempered vs. laminated, or by using concrete in its various applications (reinforced, prestressed, vs. standard usage). 
These types of activities can be the focus of in-class, summer or after school activities or special programs. They can also be inserted into existing classes if written as lesson plans and delivered by interested teachers. These activities can be enhanced or even led by us, the professionals who use this information each day in our work. As professionals, we have a lot to give as ideas and role models to educators and to students of all ages. We can also work with professional groups or local colleges to ensure that quality education includes applications of science and technology. Some excellent programs and references for educators are noted in the sample resources listing below, a listing that is in no way comprehensive but gives interested scientists and engineers a good start.

Creative genius in this area can get young and old thinking about the impact of science, technology in our society. It can also stimulate an understanding of the need for an understanding of what science is all about among those who do NOT choose a career in this area-that is, those who become an audience of citizen who support science and scientific discovery. If a basic understanding of scientific methods and of the process of researching specific topics to produce a recommendation in a specific topic. If science and the scientific method were widely understood, it would be much easier for the public to evaluate on their own the value of a policy or product.

Technologists of all varieties need to help in this endeavor by working with schools, colleges and professional groups to help make science fun for all. To enlighten those in leadership positions is a fundamental duty of all scientists and engineers. Yes, science and technology are everywhere, in nature, in the 'stuff' we use every day, and at the heart of today's technology. If we focus on education in science and its applications, as well as on our own area of expertise, we can revolutionize policy and project deliberation at both local, national and international levels.

\section{Sample Educational Resources (not comprehensive)}

Mineral Education Coalition, https://mineralseducationcoalition. org/

A variety of educational materials in mining and minerals

National Resource Center for Materials Technology Education, www.materialseducation.org:

A full set of educational modules and resources for teachers in all areas of materials education.

Materials Education Foundation of ASM International, https:// www.asmfoundation.org:

Programs and resources for teachers and students in metallurgy and materials.

Materials Explorers, https://www.materials-explorers.org:

Educational ideas for teachers in materials.

Smithsonian Science Education Center, www.ssec.si.edu:

Focus on science in the classroom.

Granta Design, www.grantadesign.com:

Provides a wide variety of educational resources in materials.

For possible submissions Click below: 